\title{
Article
}

\section{The PUB4 E3 Ubiquitin Ligase Is Responsible for the Variegated Phenotype Observed upon Alteration of Chloroplast Protein Homeostasis in Arabidopsis Cotyledons}

\author{
Nicolaj Jeran ${ }^{\dagger}$, Lisa Rotasperti ${ }^{\dagger}$, Giorgia Frabetti, Anna Calabritto, Paolo Pesaresi (i) and Luca Tadini * ${ }^{(1)}$ \\ Dipartimento di Bioscienze, Università degli Studi di Milano, 20133 Milano, Italy; nicolaj.jeran@unimi.it (N.J.); \\ lisa.rotasperti@unimi.it (L.R.); giorgia.frabetti@studenti.unimi.it (G.F.); anna.calabritto@studenti.unimi.it (A.C.); \\ paolo.pesaresi@unimi.it (P.P.) \\ * Correspondence: luca.tadini@unimi.it \\ † These authors equally contributed to the article.
}

Citation: Jeran, N.; Rotasperti, L.; Frabetti, G.; Calabritto, A.; Pesaresi, P.; Tadini, L. The PUB4 E3 Ubiquitin Ligase Is Responsible for the Variegated Phenotype Observed upon Alteration of Chloroplast Protein Homeostasis in Arabidopsis Cotyledons. Genes 2021, 12, 1387. https://doi.org/10.3390/ genes12091387

Academic Editors: Paola Vittorioso, Ignacio Ezquer and Stefan de Folter

Received: 13 August 2021

Accepted: 3 September 2021

Published: 6 September 2021

Publisher's Note: MDPI stays neutral with regard to jurisdictional claims in published maps and institutional affiliations.

Copyright: (c) 2021 by the authors. Licensee MDPI, Basel, Switzerland. This article is an open access article distributed under the terms and conditions of the Creative Commons Attribution (CC BY) license (https:// creativecommons.org/licenses/by/ $4.0 /)$.

\begin{abstract}
During a plant's life cycle, plastids undergo several modifications, from undifferentiated pro-plastids to either photosynthetically-active chloroplasts, ezioplasts, chromoplasts or storage organelles, such as amyloplasts, elaioplasts and proteinoplasts. Plastid proteome rearrangements and protein homeostasis, together with intracellular communication pathways, are key factors for correct plastid differentiation and functioning. When plastid development is affected, aberrant organelles are degraded and recycled in a process that involves plastid protein ubiquitination. In this study, we have analysed the Arabidopsis gun1-102 ftsh5-3 double mutant, lacking both the plastidlocated protein GUN1 (Genomes Uncoupled 1), involved in plastid-to-nucleus communication, and the chloroplast-located FTSH5 (Filamentous temperature-sensitive H5), a metalloprotease with a role in photosystem repair and chloroplast biogenesis. gun1-102 ftsh5-3 seedlings show variegated cotyledons and true leaves that we attempted to suppress by introgressing second-site mutations in genes involved in: (i) plastid translation, (ii) plastid folding/import and (iii) cytosolic protein ubiquitination. Different phenotypic effects, ranging from seedling-lethality to partial or complete suppression of the variegated phenotype, were observed in the corresponding triple mutants. Our findings indicate that Plant U-Box 4 (PUB4) E3 ubiquitin ligase plays a major role in the target degradation of damaged chloroplasts and is the main contributor to the variegated phenotype observed in gun1-102 ftsh5-3 seedlings.
\end{abstract}

Keywords: chloroplast; ubiquitination; variegated phenotype; protein homeostasis

\section{Introduction}

Albinotic and variegated mutants have been widely used to investigate chloroplast biogenesis and the communication pathways between the nuclear-cytosolic compartment and chloroplasts [1-3]. Among these, Arabidopsis ftsh5 (var1) and ftsh2 (var2) mutants, devoid of two subunits of the thylakoid transmembrane metalloprotease complex FTSH (Filamentation Temperature Sensitive protein H), responsible for photosystem II (PSII) biogenesis and repair, and characterized by a leaf variegated phenotype, contributed greatly in revealing the strict link between chloroplast protein homeostasis and proper chloroplast biogenesis [4-8]. Transmission electron microscopy analyses of ftsh 2 and ftsh 5 leaves revealed, indeed, correctly-shaped chloroplasts in the green sectors, while the white sectors showed miss-shaped plastids with highly vacuolated organelle structures [6,9]. Furthermore, second-site suppressor screens aimed to identify mutations able to suppress the ftsh leaf variegated phenotype, so-called Suppressors of Variegation (SVR), allowed the identification of several nuclear genes encoding plastid-located proteins mostly involved in rRNA maturation, translation, protein folding and protein degradation [3,10-14]. Overall, these findings indicated that the differentiation of functional chloroplasts requires an 
optimal balance between the rate of plastid protein synthesis and the activity of the plastid protein quality control machinery [15].

Recently, the variegated phenotype was also observed in cotyledons of ftsh 2 and ftsh 5 seedlings upon introgression of the gun 1 knock-out mutation (for further details see Tadini et al. [16]). GUN1 is a chloroplast-localized pentatricopeptide repeat (PPR) protein required during the early stages of chloroplast biogenesis and upon alterations of plastid gene expression and chloroplast protein homeostasis [16-21]. In particular, gun1 ftsh 2 cotyledons are characterized by the presence of highly vacuolated plastids, without any traces of thylakoid membranes, while gun 1 ftsh 5 cotyledons show a less severe albino-variegated phenotype and possess cells with either functional chloroplasts or plastids with budding vesicles, an evidence of the ongoing plastid degradation process [16].

Recent studies have highlighted that the ubiquitin-dependent modification of proteins located on the chloroplast outer membrane is a pivotal event, at the basis of chloroplast adaptation to stress conditions, involving either targeted protein removal through the ubiquitin-proteasome system, or selective, whole-chloroplast degradation, based on the severity of the chloroplast damages [22-24]. Suppressor of PPI1 locus1 (SP1) and Plant U-Box 4 (PUB4) are the two main E3 ubiquitin ligases reported to be involved in chloroplast ubiquitination, so far $[22,24,25]$. SP1 is embedded in the outer envelope of the chloroplast and, by ubiquitination of Translocon of Outer membrane of Chloroplast (TOC) components, confers the ability to isolate the chloroplasts from the bulk of plastid precursor proteins in the cytoplasm, thus modulating the quantity and the quality of the imported preproteins $[22,23,26]$. On the other hand, PUB4 is soluble in the cytoplasm and acts on still unidentified proteins located on the chloroplast outer envelope, serving to target damaged chloroplasts for degradation in response to ROS stress. This would provide a chloroplast quality control mechanism to reduce the risk of further ROS accumulation [24,27].

In this work we attempted to suppress the variegated phenotype of gun1-102 ftsh5-3 cotyledons through the introgression of additional mutations in nuclear genes, encoding proteins with roles in: (i) plastid translation, (ii) plastid folding/import and (iii) cytosolic protein ubiquitination. We demonstrated that the introgression of pub4-7 mutation into the gun1-102 ftsh5-3 genetic background suppresses the variegated phenotype of gun1-102 ftsh5-3 cotyledons. In particular, the degenerating gun1-102 ftsh5-3 plastids are replaced by functional chloroplasts in gun1-102 ftsh5-3 pub4-7 cotyledons, indicating that the PUB4-dependendent chloroplast quality control mechanism is active in gun1-102 ftsh5-3 cotyledons and is at the basis of the variegated phenotype.

\section{Materials and Methods}

\subsection{Plant Material and Growth Conditions}

Arabidopsis (Arabidopsis thaliana, genetic background Col-0) wild-type and mutant seeds were grown on soil in a climate chamber under long-day conditions $(16 \mathrm{~h}$ at $100 \mu \mathrm{mol}$ photons $\mathrm{m}^{-2} \mathrm{~s}^{-1}$ light and $8 \mathrm{~h}$ dark, at $22{ }^{\circ} \mathrm{C}$ temperature). Genetic loci and T-DNA flanking regions of insertional mutant lines used in this work are described in Figure S1. Primer sequences for genotype determination are listed in Table S1. Multiple mutants were generated by manual crossing and identified by PCR-based segregation analyses of F2 populations, with the only exception being the gun1-102 ftsh5-3 pub4-7 mutant, where the pub4-7 mutant allele was generated using the CRISPR-Cas9 genome editing strategy. In particular, the gun1-102 ftsh5-3 pub4-7 triple mutant was generated by targeting the fourth exon of the PUB4 locus in the gun1-102 ftsh5-3 mutant background using the pHEE401E vector described by Xing et al. [28]. Mutant plants carrying the mutation of interest and devoid of the Cas9 endonuclease were selected in the T3 generation. Primer sequences used for guide RNA design are listed in Table S1. Cotyledon and leaf area were determined by the ImageJ software (http:/ /imagej.nih.gov/ij/index.html, accessed on 15 August 2021). The Variegation Index (V.I.) was calculated as the ratio of green area over the total area of the organ. 


\subsection{Chlorophyll Fluorescence Measurements and Chlorophyll Quantification}

The imaging Chl fluorometer (Walz Imaging PAM; https: / walz.com/, accessed on 15 August 2021) was used to measure in vivo Chl a fluorescence. Six plants of each genotype were analyzed at 6 and 12 days after sowing (DAS) and average values plus-minus standard deviations were calculated. Dark-adapted plants were exposed to blue measuring beam (intensity 4) and a saturating light flash (intensity 4) to obtain the maximum quantum yield of PSII, Fv/Fm. A 5-min exposure to actinic light $\left(36 \mu \mathrm{mol}\right.$ photons $\left.\mathrm{m}^{-2} \mathrm{~s}^{-1}\right)$ allowed for the calculation of the effective quantum yield of PSII, $\mathrm{Y}_{\mathrm{II}}$. For Chl quantification, $100 \mathrm{mg}$ (fresh weight) of 6 DAS seedlings were ground in liquid nitrogen and extracted in $90 \%$ acetone. Chlorophyll (Chl) a and b concentrations were measured according to Porra et al. [29]. Measurements were performed in triplicate.

\subsection{Transmission Electron Microscopy (TEM) Analyses}

For TEM observations, tissue samples from fully expanded cotyledons of Col-0, ftsh5-3, pub4-2 and gun1-102 ftsh5-3 pub4-7 seedlings were prepared according to Tadini et al. [16]. In particular, 6 DAS seedlings were fixed in 3.3\% $(v / v)$ paraformaldehyde and $1.2 \%(v / v)$ glutaraldehyde in $0.1 \mathrm{M}$ phosphate buffer ( $\mathrm{pH} 7.4$ ) at $4{ }^{\circ} \mathrm{C}$ for $2 \mathrm{~h}$ and post-fixed in $1 \%$ $\mathrm{OsO}_{4}$ in the same buffer for $2 \mathrm{~h}$. Samples were then dehydrated in an ethanol series and embedded in Spurr's resin. Ultrathin sections were stained with $2 \%$ uranyl acetate and lead citrate and observed with a Jeol 100SX TEM (Jeol; https:/ / www.jeol.co.jp/, accessed on 15 August 2021) operating at $80 \mathrm{KV}$.

\subsection{Quantitative Real-Time PCR ( $q$ RT-PCR) Analyses}

Total RNA was isolated from 6 DAS Col-0 and mutant seedlings. For qRT-PCR analyses, $1 \mu \mathrm{g}$ of total RNA was treated with iScript ${ }^{\mathrm{TM}} \mathrm{gDNA}$ Clear cDNA Synthesis Kit (Bio-Rad; https:/ / www.bio-rad.com/, accessed on 15 August 2021) for genomic DNA digestion and first-strand cDNA synthesis. qRT-PCR analyses were performed on a CFX96 Real-Time system (Bio-Rad; https:/ / www.bio-rad.com/, accessed on 15 August 2021) using primer pairs listed in Table S1. PP2AA3 (AT1G13320) transcripts were used as internal reference, as described [30]. Data obtained from three biological and three technical replicates for each sample were analyzed with the Bio-Rad CFX Maestro 1.1 (v 4.1) (Bio-Rad; https:/ / www.bio-rad.com/, accessed on 15 August 2021).

\subsection{Protein Sample Preparation and Immunoblot Analyses}

For immunoblot analyses, cotyledons from 6 DAS seedlings were homogenized in Laemmli sample buffer (20\% [v/v] glycerol, $4 \%$ [w/v] SDS, $160 \mathrm{mM}$ Tris-HCl pH 6.8, 10\%

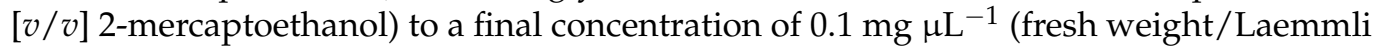
sample buffer). Samples were incubated at $65^{\circ} \mathrm{C}$ for $15 \mathrm{~min}$ and, after a centrifugation step at $16,000 \times g$ for $10 \mathrm{~min}$, the supernatant was incubated at $95^{\circ} \mathrm{C}$ for $5 \mathrm{~min}$. Protein extracts corresponding to $4 \mathrm{mg}$ (fresh-weight) seedlings were loaded onto SDS-PAGE $(10 \%[w / v]$ acrylamide) gels and transferred to polyvinylidene-difluoride (PVDF) filters $(0.20 \mu \mathrm{m}$ pore size). Replicate membranes were immuno-decorated with specific antibodies.

Intact chloroplasts were isolated from $100 \mathrm{mg}$ (fresh weight) 6 DAS seedlings according to Kunst [31], with a few changes. Samples were homogenized in $1 \mathrm{~mL}$ of $45 \mathrm{mM}$ sorbitol, $20 \mathrm{mM}$ Tricine-KOH pH 8.4, $10 \mathrm{mM}$ EDTA, $10 \mathrm{mM} \mathrm{NaHCO}_{3}$ and $0.1 \%(w / v)$ BSA fraction $\mathrm{V}$, supplemented with proteinase inhibitor cocktail (cOmplete ${ }^{\mathrm{TM}}, \mathrm{COEDTAF}-\mathrm{RO}$, Roche; https://www.roche.com/, accessed on 15 August 2021), and centrifuged for $7 \mathrm{~min}$ at $700 \times g$. The supernatant was discarded, while the pellet was washed twice with $1 \mathrm{~mL}$ of homogenization buffer. After a centrifugation step $(7 \mathrm{~min}$ at $700 \times \mathrm{g})$, the pellet was collected as the intact chloroplast fraction. The level of signals was quantified by the ImageJ software (http:/ /imagej.nih.gov/ij/index.html, accessed on 15 August 2021).

Antibodies specific for LHCB5 (AS01 009), VIPP1 (AS06 145), CLPB3 (AS09 459), cpHSC70-1 (AS08 348), CPN60 (AS12 2613), HSP90-1 (AS08 346) and UBQ11 (AS08 307A) were obtained from Agrisera (https: / /www.agrisera.com/, accessed on 15 August 2021). 
The HSC70-4 antibody was purchased from Antibodies-online (https:/ / www.antibodiesonline.com/, accessed on 15 August 2021).

\subsection{Accession Numbers}

The Arabidopsis Genome Initiative accession numbers for the genes mentioned in this work can be found at TAIR (https: / / www.arabidopsis.org/, accessed on 15 August 2021): GUN1 (AT2G31400), FTSH5 (AT5G42270), FUG1 (AT1G17220), PRPS21 (AT3G27160), cpHSC70-1 (AT4G24280), SP1 (AT1G63900), PUB4 (AT2G23140), PP2AA3 (AT1G13320) and HSFA2 (AT2G26150).

\section{Results}

3.1. The Cytosolic E3 Ubiquitin Ligase PUB4 Is Responsible for the Variegated Phenotype Observed in Cotyledons and Leaves of gun1-102 ftsh5-3 Seedlings

To dissect the molecular mechanisms responsible for the variegated phenotype observed in gun1-102 ftsh5-3 cotyledons and true leaves, as a consequence of chloroplast protein homeostasis perturbation ([16]; Figures 1a and 2a), we introgressed mutations in genes involved in: (i) plastid translation, fug1-3 and prps21-1 [32,33]; (ii) plastid protein folding/import, cphsc70-1 [34,35]; (iii) cytosolic protein ubiquitination, sp1-3 and pub4-7 [22,24] (see Figure S1 and Table 1), with the aim of identifying Arabidopsis triple mutants able to suppress the gun1-102 ftsh5-3 double mutant phenotype. The large majority of the mutations investigated are caused by T-DNA insertions in the transcribed regions of the genes of interest, resulting in knock-out alleles. The only exception is represented by fug1-3 knock-down allele caused by a T-DNA insertion in the promoter region of At1g17220 locus (see Figure S1). Moreover, since the PUB4 and GUN1 loci are located on adjacent regions of chromosome 2, the PUB4 gene was silenced in the gun1-102 ftsh5-3 genetic background by using the CRISPR-Cas9 gene editing strategy. In particular, the pub4-7 allele is due to a frameshift mutation caused by the insertion of a Thymine in the fourth exon of the At2g23140 gene, in position +1804 from the transcription starting site (see Figure S1).

Table 1. List of mutant lines analysed in this study. Gene names, AGI accession numbers, subcellular localization of the gene products, functions and references where mutant alleles have been described are included.

\begin{tabular}{|c|c|c|c|c|}
\hline Gene Name & AGI Code & $\begin{array}{l}\text { Subcellular } \\
\text { Localization }\end{array}$ & Allele & Function \\
\hline GUN1 & At2g31400 & chloroplast stroma & gun1-102 [19] & $\begin{array}{l}\text { PPR protein involved in chloroplast-to-nucleus } \\
\text { communication and maintenance of plastid } \\
\text { protein homeostasis }[16-18,20] \text {. }\end{array}$ \\
\hline FTSH5 & At5g42270 & chloroplast thylakoids & ftsh5-3 [19] & $\begin{array}{l}\text { Transmembrane protease involved in thylakoid } \\
\text { biogenesis and PSII maintenance by removal of } \\
\text { damaged D1 subunit [6]. }\end{array}$ \\
\hline FUG1 & At1g17220 & chloroplast stroma & fug1-3 [32] & $\begin{array}{l}\text { Initiation factor essential for plastid protein } \\
\text { translation [32]. }\end{array}$ \\
\hline PRPS21 & At3g27160 & chloroplast stroma & prps21-1 [19] & $\begin{array}{l}\text { Structural component of the } 30 S \text { plastid ribosome } \\
\text { subunit [36]. }\end{array}$ \\
\hline cpHSC70-1 & At4g24280 & chloroplast stroma & cphsc70-1 [34] & $\begin{array}{l}\text { Plastid chaperone involved in protein import and } \\
\text { folding processes [34]. }\end{array}$ \\
\hline SP1 & At1g63900 & $\begin{array}{l}\text { cytosolic side of the } \\
\text { plastid outer envelope }\end{array}$ & $s p 1-3$ [22] & $\begin{array}{l}\text { E3 ubiquitin ligase involved in the regulation of } \\
\text { plastid protein import and component of } \\
\text { CHLORAD, i.e., ubiquitination and } \\
\text { retro-translocation of outer membrane proteins } \\
\text { for proteasome-dependent degradation [22]. }\end{array}$ \\
\hline PUB4 & At2g23140 & cytosol & $\begin{array}{c}\text { pub4-2 [24] } \\
\text { pub4-7 [This work] }\end{array}$ & $\begin{array}{l}\text { E3 ubiquitin ligase associated with the selective } \\
\text { degradation of ROS-damaged chloroplasts [24]. }\end{array}$ \\
\hline
\end{tabular}


a

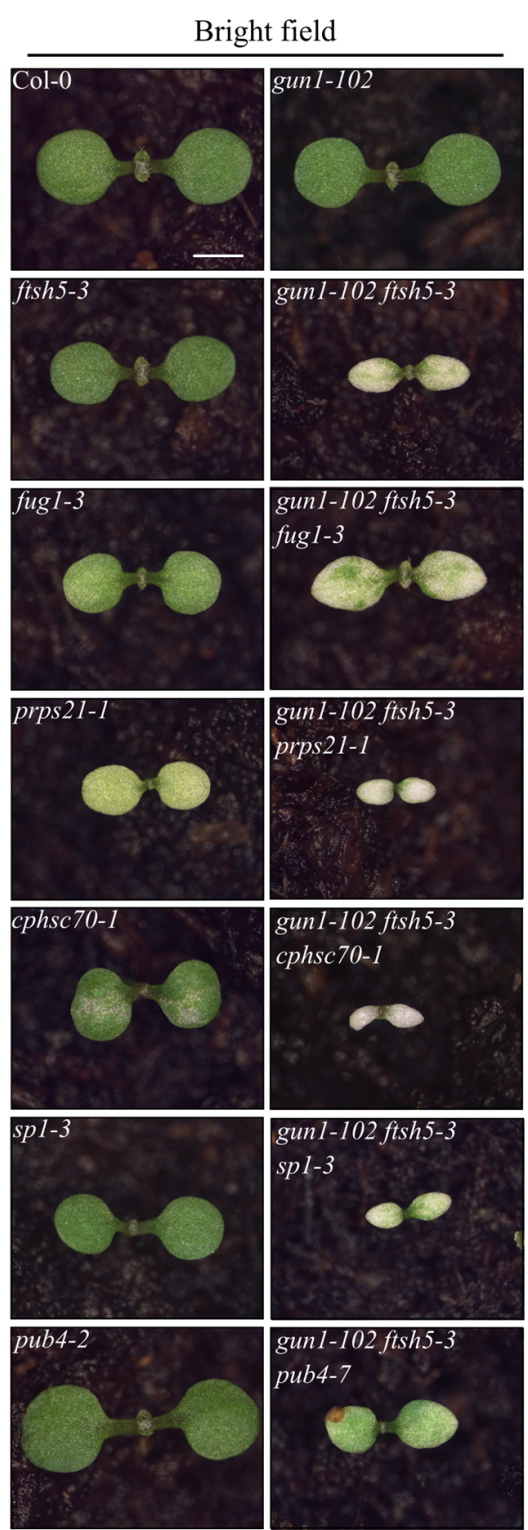

b

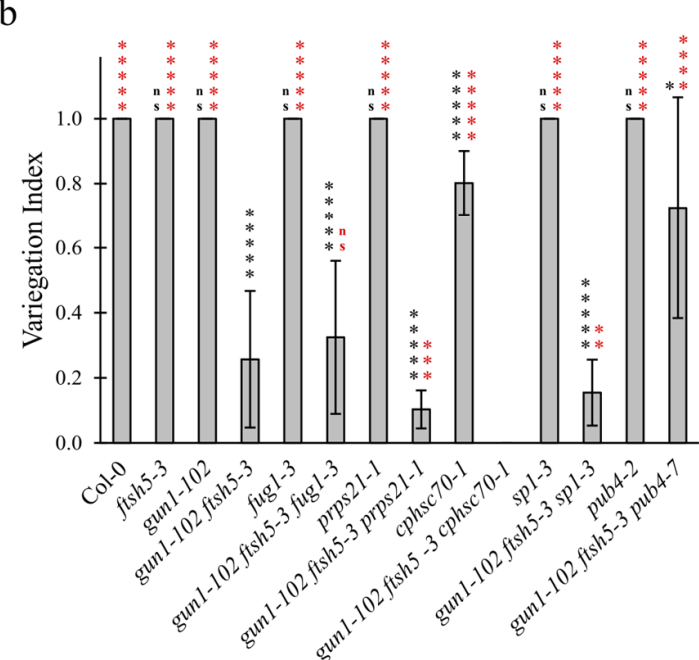

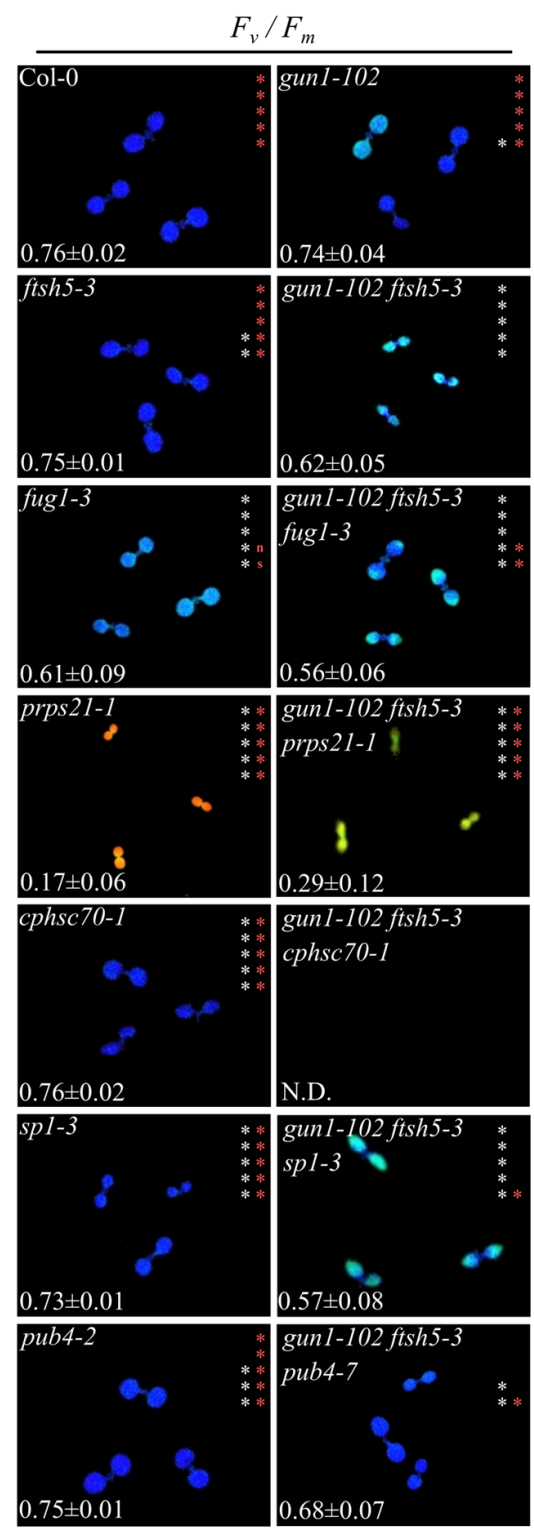

c

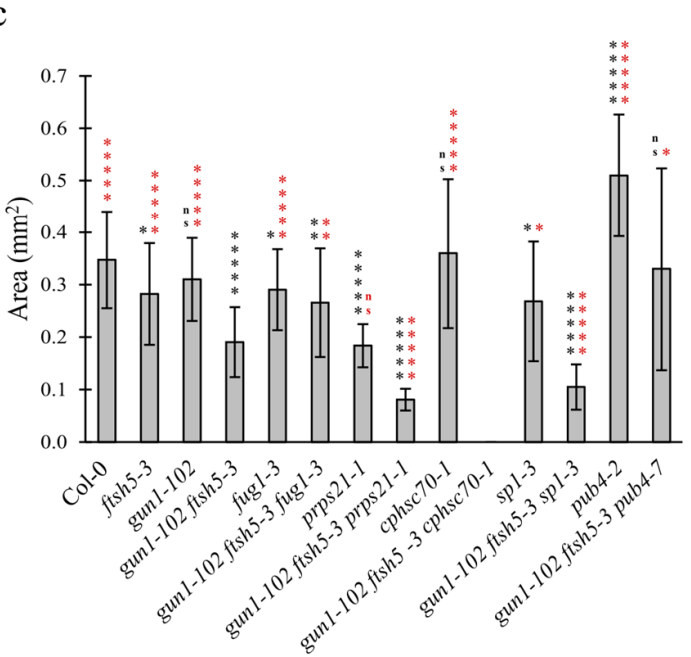

Figure 1. Visible phenotypic characteristics and photosynthetic performance of Arabidopsis Col-0 and mutant seedlings at 
cotyledon stage. (a) Visible phenotypes and maximum quantum yield of PSII $\left(F_{v} / F_{m}\right)$ of Col-0, gun1-102, ftsh5-3, gun1-102 ftsh5-3, fug1-3, gun1-102 ftsh5-3 fug1-3, prps21-1, gun1-102 ftsh5-3 prps21-1, cphsc70-1, gun1-102 ftsh5-3 cphsc70-1, sp1-3, gun1-102 ftsh5-3 sp1-3, pub4-2, gun1-102 ftsh5-3 pub4-7 cotyledons at six days after sowing (DAS) grown on soil. Scale bar corresponds to $1 \mathrm{~mm}$. $F_{v} / F_{m}$ parameter was measured through the IMAGING PAM Fluorimeter (Walz) and reported both in false colour (black equals to 0 , violet to 1 ) and as average \pm standard deviation of six independent measurements; N.D.: not detected. Asterisks indicate statistical significance with respect to Col-0 (white) or gun1-102 ftsh5-3 (red) as evaluated by Student's $t$-test and Welch correction $\left({ }^{*} p<0.05 ;{ }^{* *} p<0.01\right.$; ${ }^{* * *} p<0.001$; ${ }^{* * * *} p<0.0001$; ${ }^{* * * * *} p<0.00001$; ns: not significant). (b) Average Variegation Index (V.I.) calculated as ratio between the green area over the total area of the cotyledon of Col-0 and mutant seedlings grown on soil at 6 DAS. Error bars indicate standard deviations of at least six independent measurements. Asterisks indicate statistical significance with respect to Col-0 (black) or gun1-102 ftsh5-3 (red) as evaluated by Student's t-test and Welch correction $\left({ }^{*} p<0.05 ;{ }^{* *} p<0.01{ }^{* * *} p<0.001 ; * * * *<0.0001\right.$; ${ }^{* * * * *} p<0.00001$; ns: not significant). (c) Average area in $\mathrm{mm}^{2}$ of single cotyledons of the indicated genotypes grown on soil at 6 DAS. Error bars indicate standard deviations of at least six independent measurements. Asterisks indicate statistical significance with respect to Col-0 (black) or gun1-102 ftsh5-3 (red) as evaluated by Student's $t$-test and Welch correction $\left({ }^{*} p<0.05 ;{ }^{* *} p<0.01\right.$; ${ }^{* * *} p<0.001 ;{ }^{* * * *} p<0.0001 ;{ }^{* * * *} p<0.00001$; ns: not significant).

The obtained triple mutants were analysed at 6 DAS (Figure 1) and 12 DAS (Figure 2) to evaluate the Variegation Index (V.I.; see also Materials and Methods) and the total organ area in cotyledons and the first true leaves (Figures $1 b, c$ and $2 b, c)$. Furthermore, the functionality of chloroplasts was also assessed by determining their photosynthetic performance through the measurement of $F_{v} / F_{m}$ (Maximum quantum yield of PSII) and $\mathrm{Y}_{\mathrm{II}}$ (Effective quantum yield of PSII) parameters (Figures 1a, 2a and S2a), (b). Strikingly, the gun1-102 ftsh5-3 pub4-7 triple mutant was the only one showing a marked improvement of all the considered parameters at 6 and 12 DAS.

The significant increase in V.I. in both cotyledons and leaves, as well as the higher values of both $\mathrm{F}_{\mathrm{V}} / \mathrm{F}_{\mathrm{m}}$ and $\mathrm{Y}_{\mathrm{II}}$ parameters, together with the increased total area of both cotyledons and first true leaves (see Figures $1 c$ and 2c), indicated that the pub4-7 allele in gun1-102 ftsh5-3 pub4-7 seedlings was the only second-site mutation able to suppress the variegated phenotype of gun1-102 ftsh5-3 cotyledons and leaves. Indeed, gun1-102 ftsh5-3 prps21-1 seedlings showed an even exacerbated phenotype in terms of V.I. and photosynthetic performance at the cotyledon stage, while the gun1-102 ftsh5-3 cphsc70-1 triple mutant exhibited seedling lethality. In the latter case, the few seedlings able to germinate showed reduced white cotyledons virtually devoid of chloroplasts, as their photosynthetic parameters were undetectable. Only in the case of gun1-102 ftsh5-3 sp1-3 and gun1-102 ftsh5-3 fug1-3 cotyledons was the non-additive effect observed in terms of variegation and photosynthetic parameters. However, the total area of cotyledons slightly increased in gun1-102 ftsh5-3 fug1-3. Conversely, introgression of sp1-3 led to a small but significant reduction in cotyledon size while, at 12 DAS, the first true leaves of gun1-102 ftsh5-3 sp1-3 plants were notably smaller than those of gun1-102 ftsh5-3. Interestingly, gun1-102 ftsh5-3 prps 21-1 and gun1-102 ftsh5-3 fug1-3 true leaves showed a statistically significant increase in V.I. in comparison with the leaves of gun1-102 ftsh5-3 double mutant, indicating that both the plastid protein synthesis rate and cytosolic protein ubiquitination could contribute to the onset of leaf variegation, upon perturbation of chloroplast protein homeostasis. 


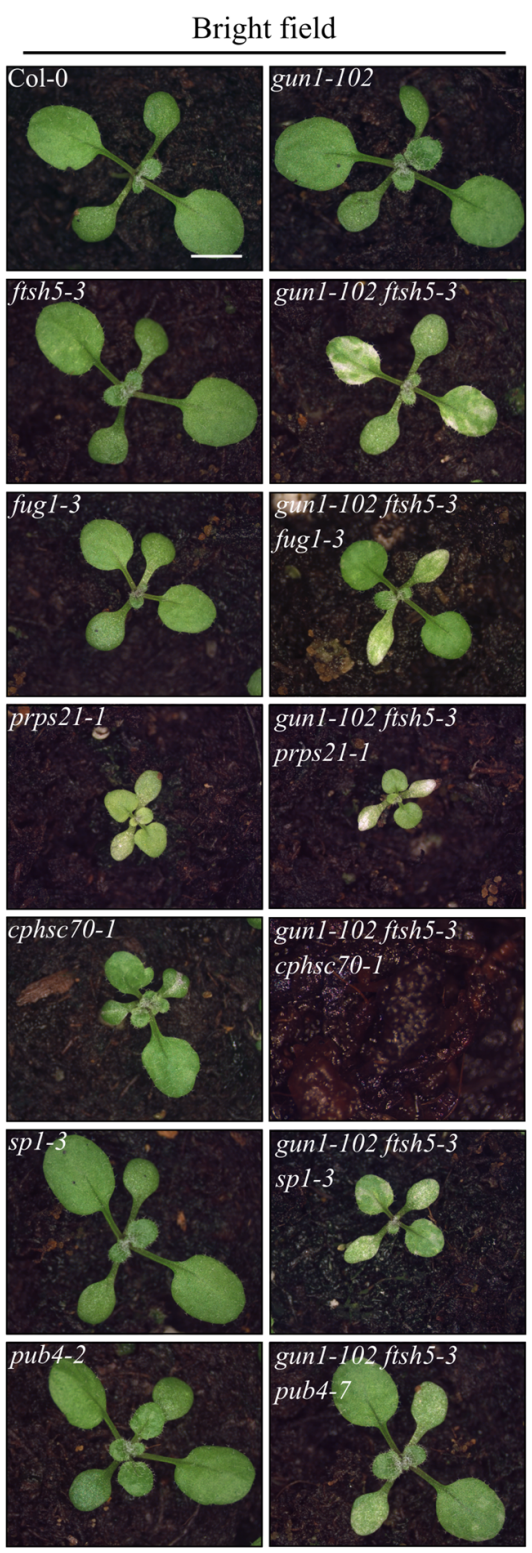

b

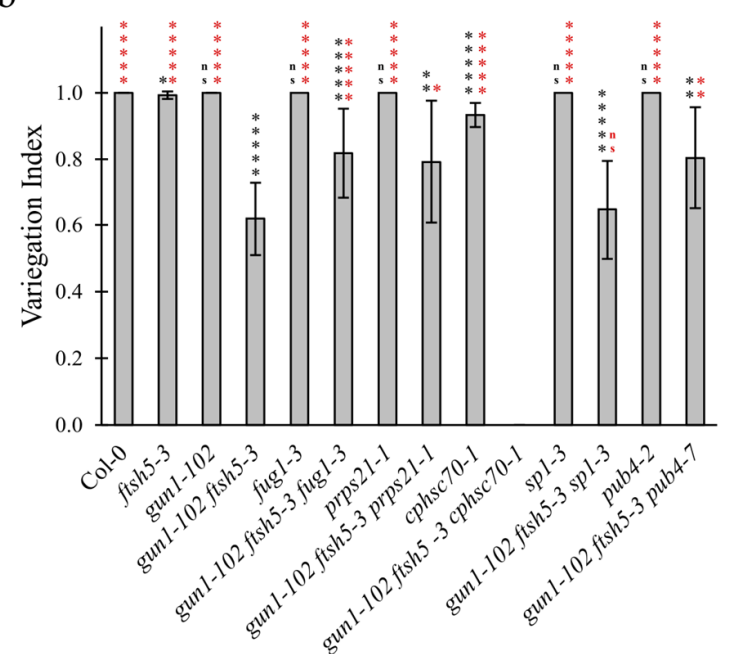

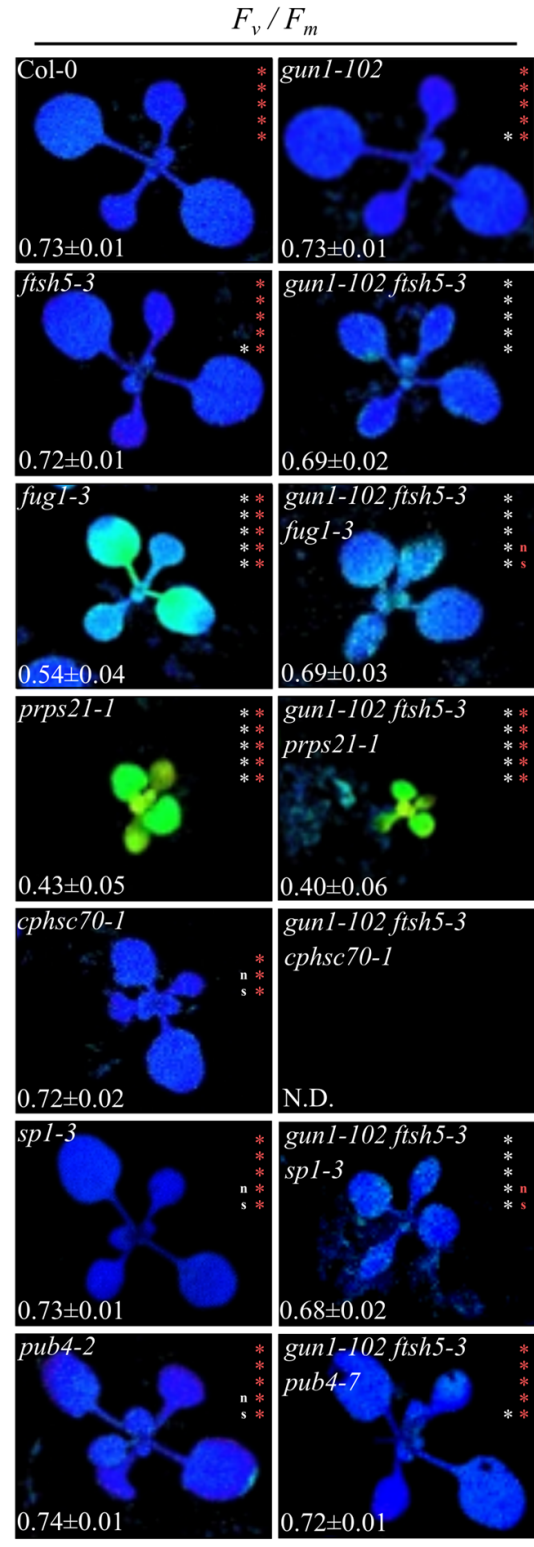

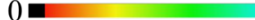

c

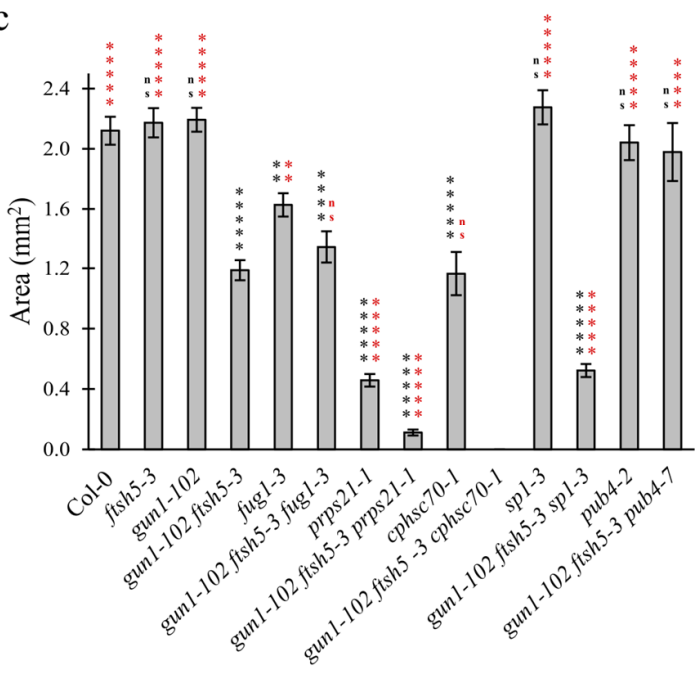

Figure 2. Visible phenotypic characteristics and photosynthetic performance of Arabidopsis Col-0 and mutant seedlings at 
two-leaves stage. (a) Visible phenotypes and maximum quantum yield of PSII $\left(F_{v} / F_{m}\right)$ of Col-0, gun1-102, ftsh5-3, gun1-102 ftsh5-3, fug1-3, gun1-102 ftsh5-3 fug1-3, prps21-1, gun1-102 ftsh5-3 prps21-1, cphsc70-1, gun1-102 ftsh5-3 cphsc70-1, sp1-3, gun1-102 ftsh5-3 sp1-3, pub4-2 and gun1-102 ftsh5-3 pub4-7 true leaves at 12 days after sowing (DAS) grown on soil. Scale bar corresponds to $1 \mathrm{~cm} . F_{v} / F_{m}$ parameter was measured through the IMAGING PAM Fluorimeter (Walz) and reported in false colour (black equals to 0 , violet to 1 ) and as average \pm standard deviation of at least six independent measurements; N.D.: not detected. Asterisks indicate statistical significance with respect to Col-0 (white) or gun1-102 ftsh5-3 (red) as evaluated by Student's $t$-test and Welch correction $\left({ }^{*} p<0.05 ;{ }^{* *} p<0.01\right.$; ${ }^{* * *} p<0.001$; ${ }^{* * * *} p<0.0001$; ${ }^{* * * *} p<0.00001$; ns, not significant). (b) Average Variegation Index (V.I.) calculated as ratio between green area and total area of the leaf of Col-0 and mutants grown on soil at 12 DAS. Error bars indicate standard deviations of at least six independent measurements. Asterisks indicate statistical significance with respect to Col-0 (black) or gun1-102 ftsh5-3 (red) as evaluated by Student's $t$-test and Welch correction $\left({ }^{*} p<0.05 ;{ }^{* *} p<0.01{ }^{* * *} p<0.001{ }^{* * * *} p<0.0001\right.$; ${ }^{* * * * *} p<0.00001$; ns: not significant). (c) Average area in $\mathrm{mm}^{2}$ of single first leaves of the indicated genotypes grown on soil at 12 DAS. Error bars indicate standard deviations of at least six independent measurements. Asterisks indicate statistical significance with respect to Col-0 (black) or gun1-102 ftsh5-3 (red) as evaluated by Student's t-test and Welch correction $\left({ }^{*} p<0.05 ;{ }^{* *} p<0.01{ }^{* * *} p<0.001 ;{ }^{* * *} p<0.0001\right.$; $* * * * * p<0.00001 ;$ ns: not significant).

\subsection{PUB4 E3 Ubiquitin Ligase Plays a Major Role in Chloroplast Degradation upon Alteration of Plastid Protein Homeostasis}

To further investigate the role of PUB4 as a component of the chloroplast quality control machinery (see also [16]), thin sections of cotyledons from the Col-0, gun1-102 ftsh5-3 double mutant, pub4-2 T-DNA insertional mutant (Figure S1) and gun1-102 ftsh5-3 pub4-7 triple mutant were analysed by Transmission Electron Microscope (TEM) (Figure 3a). Chloroplasts of Col-0 and pub4-2 cotyledons appeared to be correctly shaped, with the proper thylakoid ultrastructure organization in grana stacks and stroma lamellae and abundant starch granules in the stroma, as in the case of gun1-102 and ftsh5-3 chloroplasts (Figure 3a; see also Tadini et al. [16]). In agreement with the V.I. values, several plastids devoid of thylakoid membranes and with large vesicles either inside the stroma (Figure 3a) or budding from the envelope, as also reported in Tadini et al. [16], were observed in gun1-102 ftsh5-3 cotyledon cells, indicating advanced chloroplast degradation.

On the contrary, gun1-102 ftsh5-3 pub4-7 cotyledons contained functional chloroplasts with severely altered shape, but that were still able to accumulate thylakoid membranes organized in grana and stroma lamellae and that were capable of performing photosynthesis, as proven by the accumulation of starch granules (Figure 3a). The suppression of gun1-102 ftsh5-3 variegated phenotype, achieved by the introgression of pub4-7 mutation, was also investigated by measuring the cotyledon chlorophyll content through a spectrophotometerbased assay (Figure 3b). Chlorophyll content was similar in Col-0, gun1-102, ftsh5-3 and pub4-2 cotyledons, while it was reduced to about $60 \%$ of control levels in gun1-102 ftsh5-3 seedlings. In agreement with previous observations (Figures 1 and 3a), gun1-102 ftsh5-3 pub4-7 cotyledons showed almost double the amount of chlorophyll compared to the variegated gun1-102 ftsh5-3 cotyledons. 


\subsection{The Absence of PUB4 E3 Ubiquitin Ligase Activity Increases Cytosolic Protein Folding Stress}

Immunoblot analyses of total protein extracts from Col-0, gun1-102, ftsh5-3, pub4-2, gun1-102 ftsh5-3 and gun1-102 ftsh5-3 pub4-7 cotyledons were performed to monitor the accumulation of components of the thylakoid electron transport chain, i.e., LHCB5, of thylakoid membrane biogenesis/maintenance, such as VIPP1 [37,38], of the plastid protein homeostasis machinery, such as CLPB3, cpHSC70-1 and CPN60 [34,39,40] and of the plastid pre-protein guidance complex and molecular markers of the cytosolic folding stress, as in the case of HSC70-4 and HSP90-1 cytosolic chaperones [17,26,41] (Figure 4a).

a
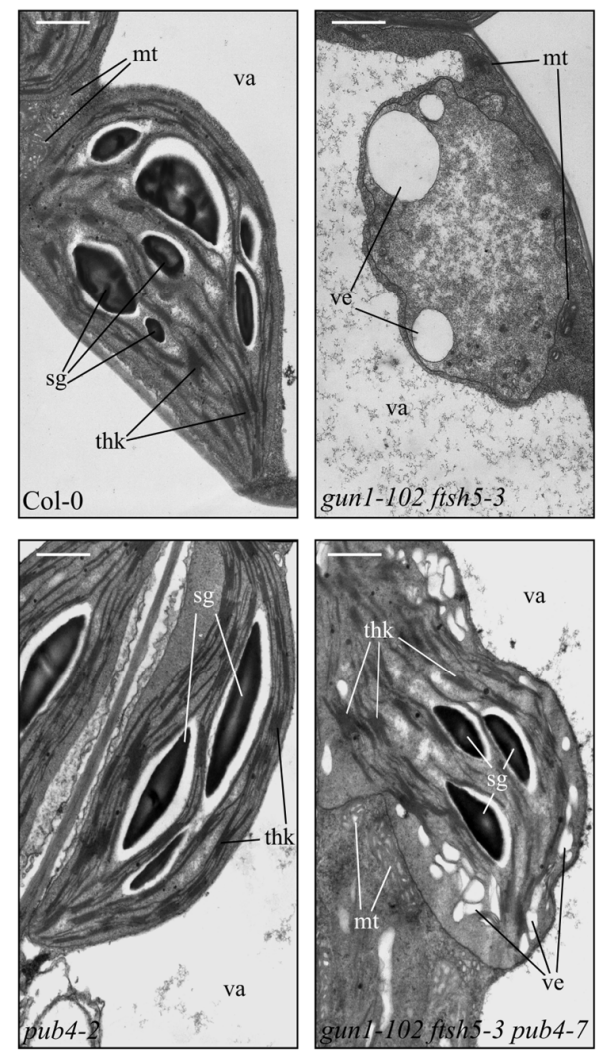

$\mathrm{b}$

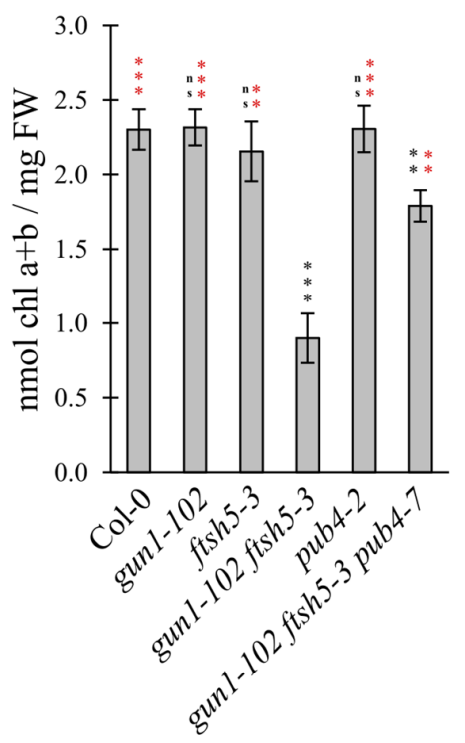

Figure 3. Chloroplast ultrastructure and chlorophyll content of Arabidopsis Col-0 and mutant cotyledons. (a) TEM micrographs of chloroplasts in mesophyll cells of Col-0, gun1-102 ftsh5-3, pub4-2 and gun1-102 ftsh5-3 pub4-7 cotyledons at 6 DAS. Ultrathin sections of cotyledons from Col-0 and mutant seedlings were stained with $2 \%$ uranyl acetate and lead citrate and examined by TEM. Scale bars correspond to $1 \mu \mathrm{m}$. The main cellular structures are indicated (sg: starch granule; thk: thylakoid membranes; ve: budding vesicles; mt: mitochondrion; va: vacuole). (b) Cotyledon chlorophyll content of the indicated Arabidopsis genotypes grown on soil at 6 DAS. The total chlorophyll content is normalised on the cotyledon fresh weight ( $\mathrm{nmol} \mathrm{Chl} \mathrm{a}+\mathrm{b} / \mathrm{mg}$ FW). Asterisks indicate statistical significance with respect to Col-0 (black) or gun1-102 ftsh5-3 (red) as evaluated by Student's $t$-test and Welch correction $(* * p<0.01 ; * * *<0.001$; ns: not significant). 


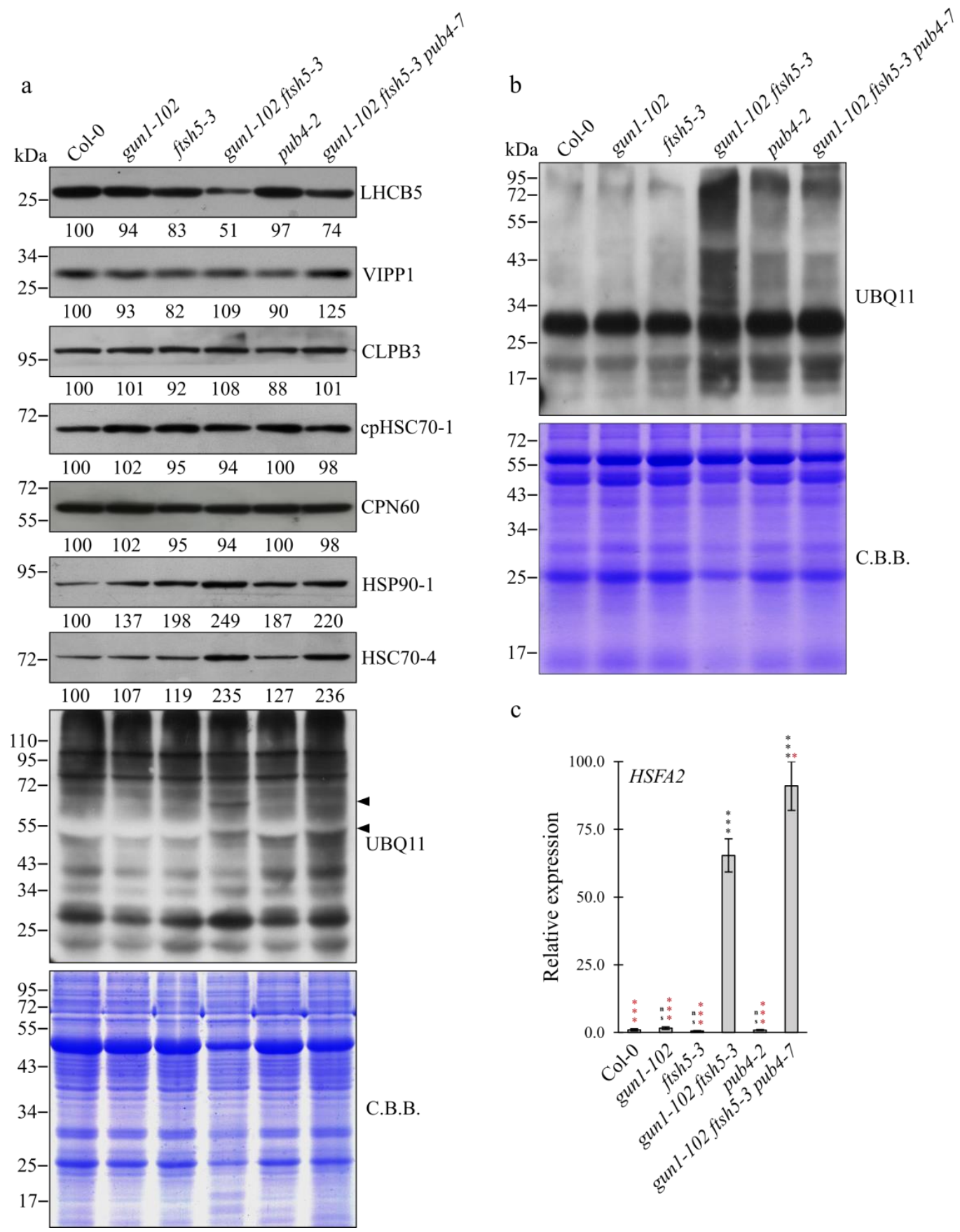

Figure 4. Protein and transcript accumulation in Arabidopsis Col-0 and mutant cotyledons. (a) Immuno-blot analyses of total protein extracts from cotyledons of Col-0, gun1-102, ftsh5-3, gun1-102 ftsh5-3, pub4-2 and gun1-102 ftsh5-3 pub4-7 grown on soil at 6 DAS. PVDF filters bearing fractionated total proteins were incubated with antibodies raised against LHCB5 antenna protein, VIPP1 plastid membrane chaperone, CLPB3 plastid unfoldase, cpHSC70-1 plastid chaperone, CPN60 plastid chaperonin, HSP90-1 cytosolic chaperone, HSC70-4 cytosolic chaperone and UBQ11 ubiquitin protein. Coomassie Brilliant Blue (CBB) stained SDS-PAGE is included as loading control. (b) Immunoblot analyses of chloroplast protein extracts from Col-0, gun1-102, ftsh5-3, gun1-102 ftsh5-3, pub4-2 and gun1-102 ftsh5-3 pub4-7 grown on soil at 6 DAS. PVDF filters bearing fractionated proteins were incubated with antibodies raised against UBQ11 ubiquitin protein. CBB-stained SDS-PAGE is included as loading control. (c) Relative expression level of HSFA2 gene determined by qRT-PCR analyses of total RNA extracted from cotyledons of Col-0, gun1-102, ftsh5-3, gun1-102 ftsh5-3, pub4-2 and gun1-102 ftsh5-3 pub4-7 grown on soil at 6 DAS. Error bars indicate standard deviations of three replicates. Asterisks indicate statistical significance with respect to Col-0 (black) or gun1-102 ftsh5-3 (red) as evaluated by Student's $t$-test and Welch correction $\left({ }^{*} p<0.05 ;{ }^{* * *} p<0.001\right.$; ns: not significant). 
In agreement with previous observations, the higher level of LHCB5 in gun1-102 ftsh5-3 pub4-7 cotyledons with respect to gun1-102 ftsh5-3 further supported the ability of pub4-7 mutation to suppress the variegated phenotype of gun1-102 ftsh5-3 cotyledons. Furthermore, the accumulation of VIPP1 appeared comparable among all the genotypes except for gun1-102 ftsh5-3 pub4-7, which showed a slight increase in VIPP1 levels, while CLPB3, cpHSC70-1 and CPN60 resulted unchanged in all the genotypes. Interestingly, the accumulation of HSC70-4 and HSP90-1 cytosolic chaperones increased markedly in both the gun1-102 ftsh5-3 double mutant and gun1-102 ftsh5-3 pub4-7 triple mutant (Figure 4a) in line with what observed in gun1 single mutant upon Lincomycin treatment [16,17], pointing to a relatively high cytosolic protein folding stress in both mutant backgrounds. Finally, the total protein ubiquitination level was assessed by a UBQ11 specific antibody. Overall, no evident difference in total signal intensity was observed between wild-type and the different mutant samples. However, the protein ubiquitination pattern in gun1-102 ftsh5-3 cotyledons showed two relatively strong bands at around 70 and $55 \mathrm{kDa}$ (see arrow heads in Figure 4a), not detectable in Col-0 and in the single mutant cotyledons. Strikingly, the band at $55 \mathrm{kDa}$ was also visible in gun1-102 ftsh5-3 pub4-7 cotyledons, while the signal at $70 \mathrm{kDa}$ disappeared in the triple mutant genetic background (Figure 4a). The lack of important discrepancies in the ubiquitination levels among all of the genotypes, even in the absence of PUB4 E3 ubiquitin ligase enzyme, prompted us to investigate whether major differences could be observed at the chloroplast level, given the ability of PUB4 to promote chloroplast degradation upon alteration of plastid protein homeostasis (see above). To this aim, intact purified chloroplasts were isolated from cotyledons of Col-0 and mutant seedlings and chloroplast proteins probed with the UBQ11 specific antibody (see Figure 4b). While chloroplast ubiquitination levels of Col-0, gun1-102 and ftsh5-3 chloroplasts were rather similar and most of the ubiquitination signal was concentrated in a single band migrating at around $30 \mathrm{kDa}$, the plastid ubiquitination levels increased largely in the gun1-102 ftsh5-3 genetic background, where signals of ubiquitinated proteins could be also detected at molecular weights different from the $30 \mathrm{kDa}$ main band (Figure $4 \mathrm{~b}$ ). Intriguingly, a large part of the increased ubiquitination signals disappeared upon depletion of PUB4 activity in gun1-102 ftsh5-3 pub4-7 chloroplasts (Figure 4b). In addition, the relative expression of HSFA2 transcription factor, a key regulator of the chloroplast-related nuclear stress response [42,43], was assessed via qRT-PCR (Figure 4c). Consistently with the increase in cytosolic chaperone accumulation (see Figure 4a), HSFA2 transcripts were strongly up-regulated in gun1-102 ftsh5-3 and, to an even larger extent, in gun1-102 ftsh5-3 pub4-7 seedlings.

\section{Discussion}

Variegated mutants represent an important genetic tool to investigate chloroplast biogenesis and to dissect the functional interactions of different pathways involved in plastid differentiation, chloroplast protein homeostasis, chloroplast quality control and degradation. In this manuscript, we studied the GUN1-mediated plastid development and degradation, in the context of altered plastid protein homeostasis, as shown by the variegated phenotype of gun1-102 ftsh5-3 seedlings.

As the gun1-102 ftsh5-3 double mutant possesses chloroplasts prone to suffer terminal damages, the recovery of gun1-102 ftsh5-3 pub4-7 phenotype observed in cotyledons and true leaves (Figures 1 and 2) suggests that PUB4-mediated ubiquitination is the preferential pathway for degrading and recycling damaged chloroplasts upon alteration of plastid protein homeostasis (Figure 5). These observations are in agreement with previous studies, in which ROS-damaged chloroplasts in Arabidopsis plants lacking the plastid ferrochelatase 2 (fc2-1) exhibited a PUB4-dependent increase in poly-ubiquitinated proteins [24]. The altered shape of chloroplasts observed in gun1-102 ftsh5-3 pub4-7 cotyledons (Figure 3a) is compatible with the early steps of the degradation process, not effectively achieved or delayed due to the absence of PUB4 protein activity, as previously reported [24]. In line with this, the up-regulation of the stress-responsive gene $H S F A 2$, here used as molecular 
marker of damaged chloroplasts and the related nuclear stress response [42,43], observed in gun1-102 ftsh5-3, was comparable or even higher in gun1-102 ftsh5-3 pub4-7, proving that pub4 mutation does not suppress the damage itself (Figure 4). It is tempting to explain the higher HSFA2 expression as a consequence of the increased number of chloroplasts in cells that, although defective, are still performing photosynthesis and, consequently, generating ROS and other stress-related signals. Worth noticing, HSFA2 expression is triggered by a GUN1-indepentent retrograde signalling pathway, as previously observed [43]. Furthermore, the introgression of pub4-7 mutation does not suppress the increased cytosolic folding stress observed in gun1-102 ftsh5-3 cotyledons (Figure 4), and previously described in gun1 seedlings upon lincomycin treatment $[16,17]$ as proven by the over-accumulation of the cytosolic chaperones HSC70-4 and HSP90-1 and the increased total protein ubiquitination level. Noteworthy is that the comparison between gun1-102 ftsh5-3 and gun1-102 ftsh5-3 pub4-7 ubiquitination profiles, performed, for example, by mass spectrometry analyses of ubiquitin-enriched protein extracts, seems to be an optimal strategy to identify those chloroplast outer envelope proteins that are modified by the PUB4 ubiquitin ligase.

On the contrary, the sp1-3 mutation, which abolishes the activity of a transmembrane ubiquitin ligase responsible for controlling TOC protein complex composition and activity, does not suppress variegation in gun1-102 ftsh5-3 cotyledons and leaves (Figures 1 and 2). SP1 activity has been recognized as essential for chloroplast biogenesis in etiolated seedlings and to play a role in the tolerance of abiotic stresses, by modulating the import rate of photosynthetic proteins, and, therefore, to prevent ROS accumulation $[22,25,26]$. In light of this, the gun1-102 ftsh5-3 sp1-3 triple mutant is devoid of an additional level of chloroplast quality control mechanism that results in an overall decrease in plant growth with respect to gun1-102 ftsh5-3 (Figures 1 and 2). Taken together, these observations corroborate the model in which ubiquitination of specific chloroplast proteins triggers different mechanisms of stress tolerance, in cotyledons and leaves, not only in response to abiotic stresses but also as adaptation to genetic defects.

The introgression of cphsc70-1 mutation, impaired in plastid protein import and protein folding [34,35], into the gun1-102 ftsh5-3 genetic background led to a complete seedling lethal phenotype. This is in agreement with previous results, as GUN1 was shown to have functional interactions with FTSH5 and cpHSC70-1 loci [16,17]. The fact that ftsh5-3 cphsc701 double mutant displays no additive phenotype compared to cphsc70-1 (Figure S3), while the gun1-102 ftsh5-3 cphsc70-1 shows seedling-lethality (Figure 1), suggests that plastid protein import, protein folding and plastid proteolysis act synergistically for achieving the correct chloroplast development and GUN1 is essential for such orchestration.

At last, in line with previous observations $[10,32,33]$, the suppression of variegated phenotype was effectively achieved in gun1-102 ftsh5-3 true leaves by reducing the plastid translation rate, driven by the introgression of either fug1-3 or prps 21-1 mutated alleles. Strikingly, this compensatory effect failed to occur in cotyledons, proving further that the pathways that underlie chloroplast biogenesis in cotyledons and leaves are characterized by substantial differences. 


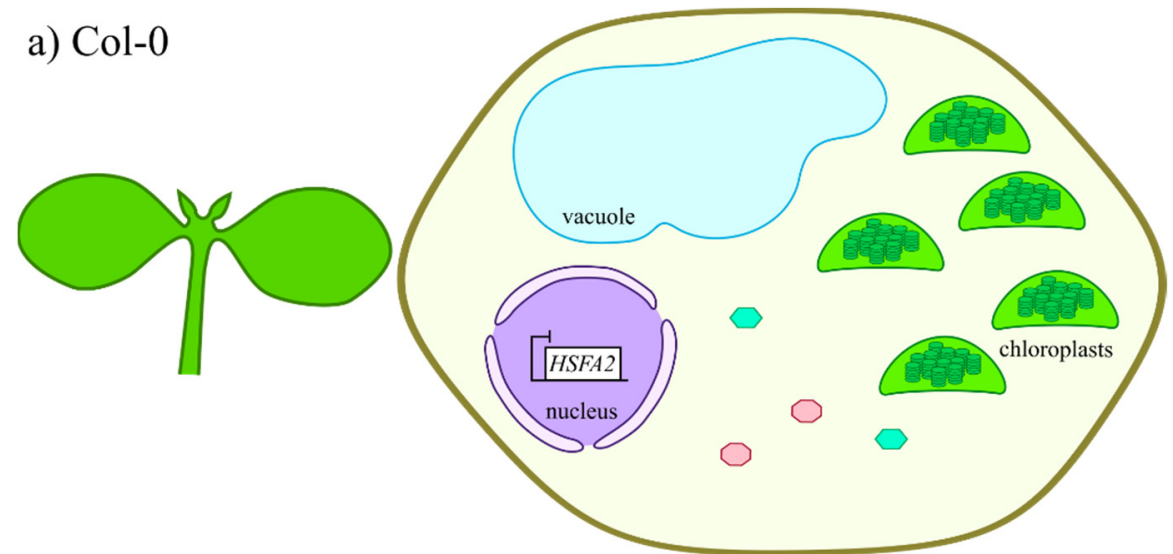

b) gun1-102 ftsh5-3

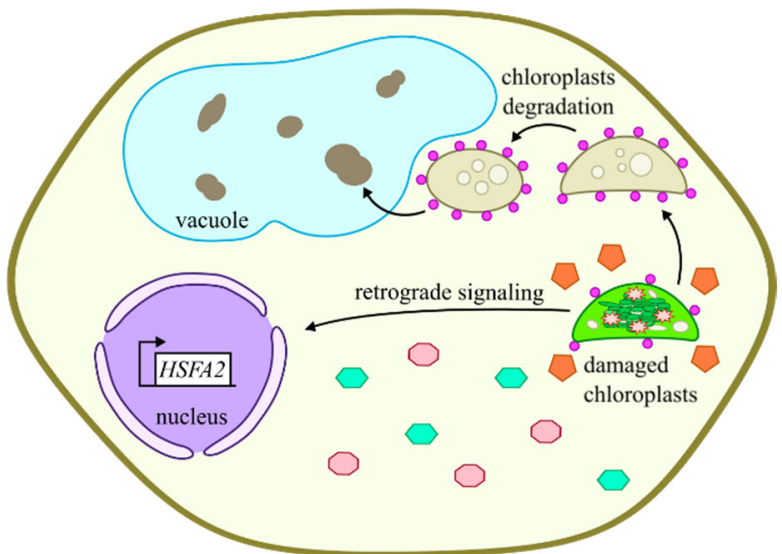

c) gun1-102 ftsh5-3 pub4-7
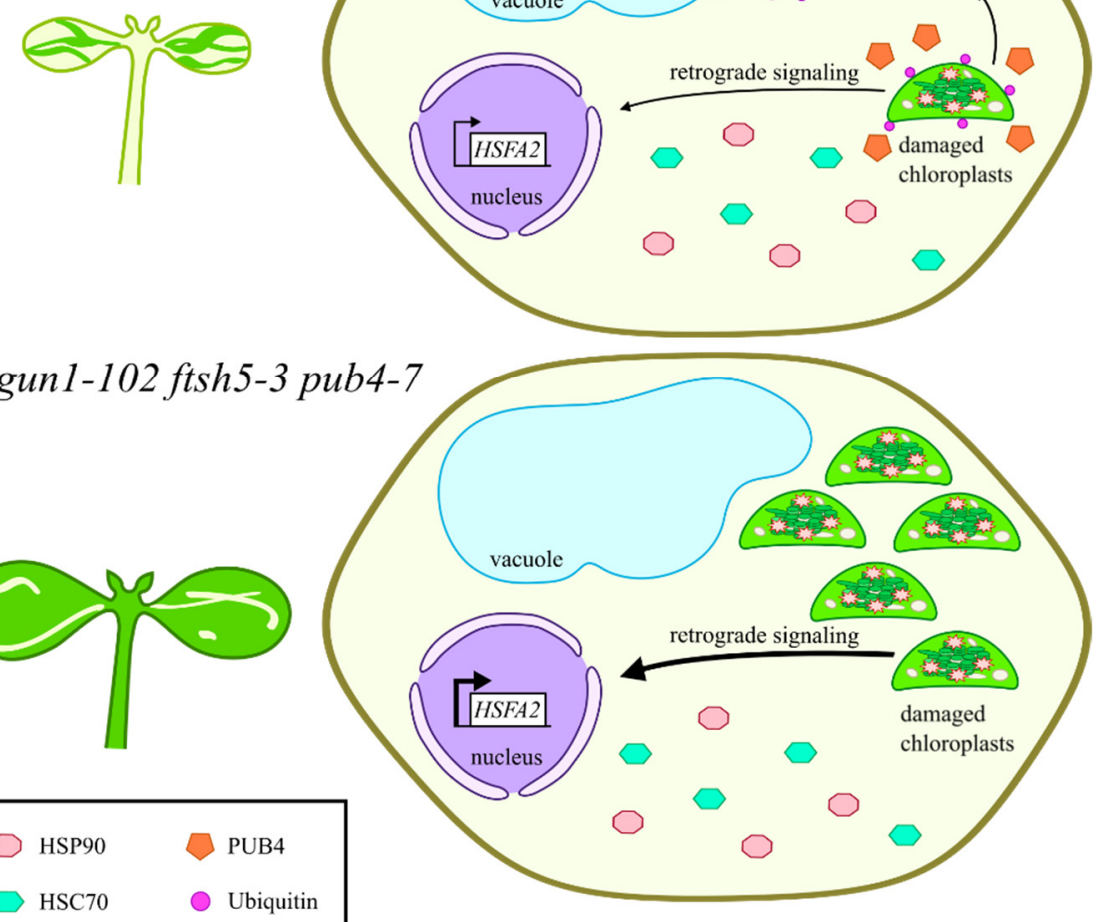

Figure 5. Schematic overview representing the pub4-mediated suppression of variegation. (a) In Col-0 seedlings, cells display functional chloroplasts, physiological cytosolic folding stress and clear vacuoles. (b) On the contrary, chloroplasts in advanced degradation stages and vacuoles filled with electron-dense material are visible in gun1-102 ftsh5-3 variegated cotyledons. The electron dense material inside the vacuole might derive from plastid degradation. The expression of the stressresponsive HSFA2 nuclear gene is strongly up-regulated, in response to signals from chloroplasts with altered protein homeostasis. Furthermore, the accumulation of cytosolic chaperones, namely HSP90 and HSC70, is increased, while the removal of damaged chloroplasts is favoured by PUB4 ubiquitin ligase. (c) The absence of PUB4 in the gun1-102 ftsh5-3 pub4-7 genetic background largely prevents the degradation of damaged chloroplasts, resulting in the suppression of variegation in both cotyledons and true leaves. Nevertheless, damaged chloroplasts, still functioning, trigger stress-related retrograde signals and lead to even higher HSFA2 expression levels. 
Supplementary Materials: The following are available online at https: / www.mdpi.com/article/ 10.3390 / genes12091387/s1, Figure S1: Graphical representations of the loci mentioned in this study, Figure S2: Photosynthetic performance of Arabidopsis Col-0 and mutant seedlings, Figure S3: Visible phenotypic characteristics and Variegation Index of Arabidopsis Col-0 and mutant seedlings at cotyledon stage, Table S1: Sequences of oligonucleotides employed for the molecular characterization of mutant lines.

Author Contributions: P.P. and L.T. designed the study. N.J., L.R., A.C. and L.T. took care of isolation of single and higher-order mutants. N.J., L.R. and G.F. took care of the phenotypical description of the mutants. N.J., L.R. and L.T. performed the molecular biology and biochemical characterization of mutants. N.J., L.R., P.P. and L.T. helped drafting the manuscript. L.T. and P.P. coordinated the study and took care of the final version of the manuscript. All authors have read and agreed to the published version of the manuscript.

Funding: This research was funded by MIUR-Ministero dell'Università e della Ricerca, grant number PRIN-2017 2017FBS8YN. The authors acknowledge support from the University of Milan through the APC initiative.

Acknowledgments: We are grateful to Francesca Lopez for critical reading of the manuscript and English editing. We are also grateful to Franco Faoro, Dario Maffi, Valerio Paravicini and Mario Beretta for excellent technical assistance.

Conflicts of Interest: The authors declare no conflict of interest.

\section{References}

1. Sakamoto, W. Leaf-variegated mutations and their responsible genes in Arabidopsis thaliana. Genes Genet. Syst. 2003, 78, 1-9. [CrossRef] [PubMed]

2. Yu, F.; Fu, A.; Aluru, M.; Park, S.; Xu, Y.; Liu, H.; Liu, X.; Foudree, A.; Nambogga, M.; Rodermel, S. Variegation mutants and mechanisms of chloroplast biogenesis. Plant Cell Environ. 2007, 30, 350-365. [CrossRef]

3. Putarjunan, A.; Liu, X.; Nolan, T.; Yu, F.; Rodermel, S. Understanding chloroplast biogenesis using second-site suppressors of immutans and var2. Photosynth. Res. 2013, 116, 437-453. [CrossRef] [PubMed]

4. Chen, M.; Choi, Y.D.; Voytas, D.F.; Rodermel, S. Mutations in the Arabidopsis VAR2 locus cause leaf variegation due to the loss of a chloroplast Ftsh protease. Plant J. 2000, 22, 303-313. [CrossRef]

5. Takechi, K.; Sodmergen; Murata, M.; Motoyoshi, F.; Sakamoto, W. The YELLOW VARIEGATED (VAR2) locus encodes a homologue of Ftsh, an ATP-dependent protease in arabidopsis. Plant Cell Physiol. 2000, 41, 1334-1346. [CrossRef]

6. Sakamoto, W.; Tamura, T.; Hanba-Tomita, Y.; Sodmergen; Murata, M. The VAR1 locus of Arabidopis encodes a choloroplastic Ftsh and is responsible for leaf variegation in the mutant alleles. Genes Cells 2002, 7, 769-780. [CrossRef] [PubMed]

7. Van Wijk, K.J. Protein maturation and proteolysis in plant plastids, mitochondria, and peroxisomes. Annu. Rev. Plant Biol. 2015, 66, 75-111. [CrossRef]

8. Nishimura, K.; Kato, Y.; Sakamoto, W. Chloroplast proteases: Updates on proteolysis within and across suborganellar compartments. Plant Physiol. 2016, 171, 2280-2293. [CrossRef]

9. Chen, M.; Jensen, M.; Rodermel, S. The yellow variegated mutant of Arabidopsis is plastid autonomous and delayed in chloroplast biogenesis. J. Hered. 1999, 90, 207-214. [CrossRef]

10. Liu, X.; Yu, F.; Rodermel, S. Arabidopsis Chloroplast Ftsh, var2 and Suppressors of var2 Leaf Variegation: A Review. J. Integr. Plant Biol. 2010, 52, 750-761. [CrossRef]

11. Wagner, R.; Aigner, H.; Funk, C. Ftsh proteases located in the plant chloroplast. Physiol. Plant 2012, 145, 203-214. [CrossRef]

12. Zheng, M.; Liu, X.; Liang, S.; Fu, S.; Qi, Y.; Zhao, J.; Shao, J.; An, L.; Yu, F. Chloroplast translation initiation factors regulate leaf variegation and development. Plant Physiol. 2016, 172, 1117-1130. [CrossRef] [PubMed]

13. Qi, Y.; Zhao, J.; An, R.; Zhang, J.; Liang, S.; Shao, J.; Liu, X.; An, L.; Yu, F. Mutations in circularly permuted GTPase family genes AtNOA1/RIF1/SVR10 and BPG2 suppress var2-mediated leaf variegation in Arabidopsis thaliana. Photosynth. Res. 2016, 127, 355-367. [CrossRef]

14. Liu, S.; Zheng, L.; Jia, J.; Guo, J.; Zheng, M.; Zhao, J.; Shao, J.; Liu, X.; An, L.; Yu, F.; et al. Chloroplast translation elongation factor EF-Tu/SVR11 is involved in Var2-mediated leaf variegation and leaf development in Arabidopsis. Front. Plant Sci. 2019, 10, 8-18. [CrossRef]

15. Sun, J.L.; Li, J.Y.; Wang, M.J.; Song, Z.T.; Liu, J.X. Protein Quality Control in Plant Organelles: Current Progress and Future Perspectives. Mol. Plant 2021, 14, 95-114. [CrossRef]

16. Tadini, L.; Peracchio, C.; Trotta, A.; Colombo, M.; Mancini, I.; Jeran, N.; Costa, A.; Faoro, F.; Marsoni, M.; Vannini, C.; et al. GUN1 influences the accumulation of NEP-dependent transcripts and chloroplast protein import in Arabidopsis cotyledons upon perturbation of chloroplast protein homeostasis. Plant J. 2020, 101, 1198-1220. [CrossRef]

17. Wu, G.Z.; Meyer, E.H.; Richter, A.S.; Schuster, M.; Ling, Q.; Schöttler, M.A.; Walther, D.; Zoschke, R.; Grimm, B.; Jarvis, R.P.; et al. Control of retrograde signalling by protein import and cytosolic folding stress. Nat. Plants 2019, 5, 525-538. [CrossRef] 
18. Koussevitzky, S.; Nott, A.; Mockler, T.C.; Hong, F.; Sachetto-Martins, G.; Surpin, M.; Lim, J.; Mittler, R.; Chory, J. Signals from Chloroplasts Converge to Regulate Nuclear Gene Expression. Science 2007, 316, 715-719. [CrossRef]

19. Tadini, L.; Pesaresi, P.; Kleine, T.; Rossi, F.; Guljamow, A.; Sommer, F.; Mühlhaus, T.; Schroda, M.; Masiero, S.; Pribil, M.; et al. GUN1 controls accumulation of the plastid ribosomal protein S1 at the protein level and interacts with proteins involved in plastid protein homeostasis. Plant Physiol. 2016, 170, 1817-1830. [CrossRef]

20. Zhao, X.; Huang, J.; Chory, J. GUN1 interacts with MORF2 to regulate plastid RNA editing during retrograde signaling. Proc. Natl. Acad. Sci. USA 2019, 116, 10162-10167. [CrossRef]

21. Tadini, L.; Jeran, N.; Pesaresi, P. GUN1 and Plastid RNA Metabolism: Learning from Genetics. Cells 2020, 9, 2307. [CrossRef]

22. Ling, Q.; Huang, W.; Baldwin, A.; Jarvis, P. Chloroplast Biogenesis Is Regulated by Direct Action of the Ubiquitin-Proteasome System. Science 2012, 338, 655-659. [CrossRef]

23. Ling, Q.; Jarvis, P. Regulation of chloroplast protein import by the ubiquitin E3 ligase SP1 is important for stress tolerance in plants. Curr. Biol. 2015, 25, 2527-2534. [CrossRef] [PubMed]

24. Woodson, J.D.; Joens, M.S.; Sinson, A.B.; Gilkerson, J.; Salomé, P.A.; Weigel, D.; Fitzpatrick, J.A.; Chory, J. Ubiquitin facilitates a quality-control pathway that removes damaged chloroplasts. Science 2015, 350, 450-454. [CrossRef] [PubMed]

25. Ling, Q.; Jarvis, P. Plant Signaling: Ubiquitin Pulls the Trigger on Chloroplast Degradation. Curr. Biol. 2016, 26, 38-40. [CrossRef]

26. Thomson, S.M.; Pulido, P.; Jarvis, R.P. Protein import into chloroplasts and its regulation by the ubiquitin-proteasome system. Biochem. Soc. Trans. 2020, 48, 71-82. [CrossRef]

27. Woodson, J.D. Chloroplast stress signals: Regulation of cellular degradation and chloroplast turnover. Curr. Opin. Plant Biol. 2019, 52, 30-37. [CrossRef]

28. Xing, H.-L.; Dong, L.; Wang, Z.-P.; Hai-Yan, Z.; Chun-Yan, H.; Bing, L.; Xue-Chen, W.; Chen, Q.-J. A CRISPR/Cas9 toolkit for multiplex genome editing in plants. BMC Plant Biol. 2014, 14, 1-12. [CrossRef]

29. Porra, R.J.; Thompson, W.A.; Kriedemann, P.E. Determination of accurate extinction coefficients and simultaneous equations for assaying chlorophylls a and b extracted with four different solvents: Verification of the concentration of chlorophyll standards by atomic absorption spectroscopy. Biochim. Biophys. Acta 1989, 975, 384-394. [CrossRef]

30. Czechowski, T.; Stitt, M.; Altmann, T.; Udvardi, M.K.; Wolf-Rüdiger, S. Genome-Wide Identification and Testing of Superior Reference Genes for Transcript Normalization in Arabidopsis. Genome Anal. 2005, 139, 5-17. [CrossRef] [PubMed]

31. Kunst, L. Preparation of physiologically active chloroplasts from Arabidopsis. Methods Mol. Biol. 1998, 82, 43-48. [CrossRef]

32. Miura, E.; Kato, Y.; Matsushima, R.; Albrecht, V.; Laalami, S.; Sakamoto, W. The balance between protein synthesis and degradation in chloroplasts determines leaf variegation in Arabidopsis yellow variegated mutants. Plant Cell 2007, 19, 1313-1328. [CrossRef]

33. Liu, X.; Zheng, M.; Wang, R.; Wang, R.; An, L.; Rodermel, S.R.; Yu, F. Genetic interactions reveal that specific defects of chloroplast translation are associated with the suppression of var2-mediated leaf variegation. J. Integr. Plant Biol. 2013, 55, 979-993. [CrossRef]

34. Latijnhouwers, M.; Xu, X.M.; Møller, S.G. Arabidopsis stromal 70-kDa heat shock proteins are essential for chloroplast development. Planta 2010, 232, 567-578. [CrossRef] [PubMed]

35. Su, P.H.; Li, H.M. Stromal Hsp70 is important for protein translocation into pea and Arabidopsis chloroplasts. Plant Cell 2010, 22, 1516-1531. [CrossRef]

36. Morita-Yamamuro, C.; Tsutsui, T.; Tanaka, A.; Yamaguchi, J. Knock-out of the plastid ribosomal protein S21 causes impaired photosynthesis and sugar-response during germination and seedling development in Arabidopsis thaliana. Plant Cell Physiol. 2004, 45, 781-788. [CrossRef]

37. Zhang, L.; Kato, Y.; Otters, S.; Vothknecht, U.C.; Sakamoto, W. Essential role of VIPP1 in chloroplast envelope maintenance in Arabidopsisw. Plant Cell 2012, 24, 3695-3707. [CrossRef]

38. Zhang, L.; Sakamoto, W. Possible function of VIPP1 in thylakoids: Protection but not formation? Plant Signal. Behav. 2013, 8. [CrossRef]

39. Myouga, F.; Motohashi, R.; Kuromori, T.; Nagata, N.; Shinozaki, K. An Arabidopsis chloroplast-targeted Hsp101 homologue, APG6, has an essential role in chloroplast development as well as heat-stress response. Plant J. 2006, 48, 249-260. [CrossRef]

40. Vitlin Gruber, A.; Nisemblat, S.; Azem, A.; Weiss, C. The complexity of chloroplast chaperonins. Trends Plant Sci. 2013, 18, 688-694. [CrossRef] [PubMed]

41. Paila, Y.D.; Richardson, L.G.L.; Inoue, H.; Parks, E.S.; McMahon, J.; Inoue, K.; Schnell, D.J. Multi-functional roles for the polypeptide transport associated domains of Toc75 in chloroplast protein import. Elife 2016, 5, 1-29. [CrossRef] [PubMed]

42. Nishizawa, A.; Yabuta, Y.; Yoshida, E.; Maruta, T.; Yoshimura, K.; Shigeoka, S. Arabidopsis heat shock transcription factor A2 as a key regulator in response to several types of environmental stress. Plant J. 2006, 48, 535-547. [CrossRef] [PubMed]

43. Llamas, E.; Pulido, P.; Rodriguez-Concepcion, M. Interference with plastome gene expression and Clp protease activity in Arabidopsis triggers a chloroplast unfolded protein response to restore protein homeostasis. PLoS Genet. 2017, $13,1-27$. [CrossRef] [PubMed] 